\title{
Effect of afterload reduction in patients with ventricular and physiological pacing
}

\author{
M BEEN, D P DE BONO, H C MILLER, W S HILLIS \\ From the Departments of Cardiology, Royal Infirmary, Edinburgh, and Stobhill Hospital, Glasgow
}

SUMMARY The effect of afterload reduction was studied in a group of patients who remained breathless or tired after permanent ventricular pacing. Haemodynamic measurements were made before and after giving hydralazine $20 \mathrm{mg}$ intravenously using a triple lumen thermodilution catheter and cuff blood pressure recordings during ventricular pacing at the standard rate of $71 / \mathrm{min}$ or an increased rate of $88 / \mathrm{min}$ and physiological pacing. Increasing the ventricular pacing rate had no effect on cardiac output as stroke volume fell. Hydralazine produced a greater rise in cardiac output than physiological pacing alone, although peak values were obtained by combining the two. Ventricular pacing produced intermittent large left and right atrial pressure peaks. Physiological pacing produced no such peaks, and mean right and left atrial pressures fell. Hydralazine did not significantly alter atrial pressures.

These findings show that in these patients, most of whom had a low cardiac output, afterload reduction with ventricular pacing increased resting cardiac output more than physiological pacing alone. Nevertheless, persistence of high filling pressures despite afterload reduction may limit the potential therapeutic benefit. Care should be taken in extrapolating these data to other patient groups.

Technical improvement in dual chamber pacing systems is leading to their more widespread use and to a parallel increase in controversy regarding the indications for atrioventricular pacing. ${ }^{2}$ Atrioventricular sequential pacing has been shown to give a higher cardiac output than conventional ventricular pacing in patients with complete heart block after cardiac surgery ${ }^{3}$ or acute myocardial infarction. ${ }^{4}$ Greenberg et al, however, found an inverse relation between left ventricular end diastolic pressure and the atrial contribution to ventricular filling and suggested that patients with poor left ventricular function may show the smallest increase in cardiac output with atrioventricular pacing. ${ }^{5}$ Apart from maintaining the proper relation between atrial and ventricular systole, true "physiological" pacing also implies an ability to increase heart rate appropriately on demand; during exercise increases in heart rate may become relatively more important than atrioventricular synchrony. ${ }^{67}$

The identification of subgroups of patients who would particularly benefit from permanent physiolog-

Requests for rep̀rints to Dr M Been, Department of Cardiology, Royal Infirmary, Edinburgh EH3 9YW.

Accepted for publication 18 October 1983 ical pacing is still controversial. Most patients are not overtly symptomatic with ventricular pacing, and despite showing an improvement in resting cardiac output with atrioventricular pacing some studies have claimed that the practical benefit in terms of increased exercise tolerance may be less pronounced ${ }^{8}$ or absent. ${ }^{9}$ In contrast Perrins et al recently reported a $27 \%$ increase in exercise performance. ${ }^{10}$ As physiological pacing systems are still relatively expensive both in capital cost and in follow up requirements, we questioned whether similar benefits to those achieved with physiological pacing might be obtained by combining a simple ventricular pacing system with drug treatment to reduce left ventricular afterload. In view of the extensive use of afterload reduction in treating cardiac failure, ${ }^{11}$ we also investigated the interaction between this treatment and ventricular or physiological pacing.

In this study we compared the acute changes in cardiac output, right atrial pressure, pulmonary artery wedge pressure, and systemic blood pressure that occurred during ventricular pacing at different rates with those during atrial triggered ventricular pacing (VAT mode) in a group of patients with impaired left ventricular function. Measurements 
able 1 Mean $( \pm S D)$ values of paired haemodynamic variables before and after treatment with hydralazine

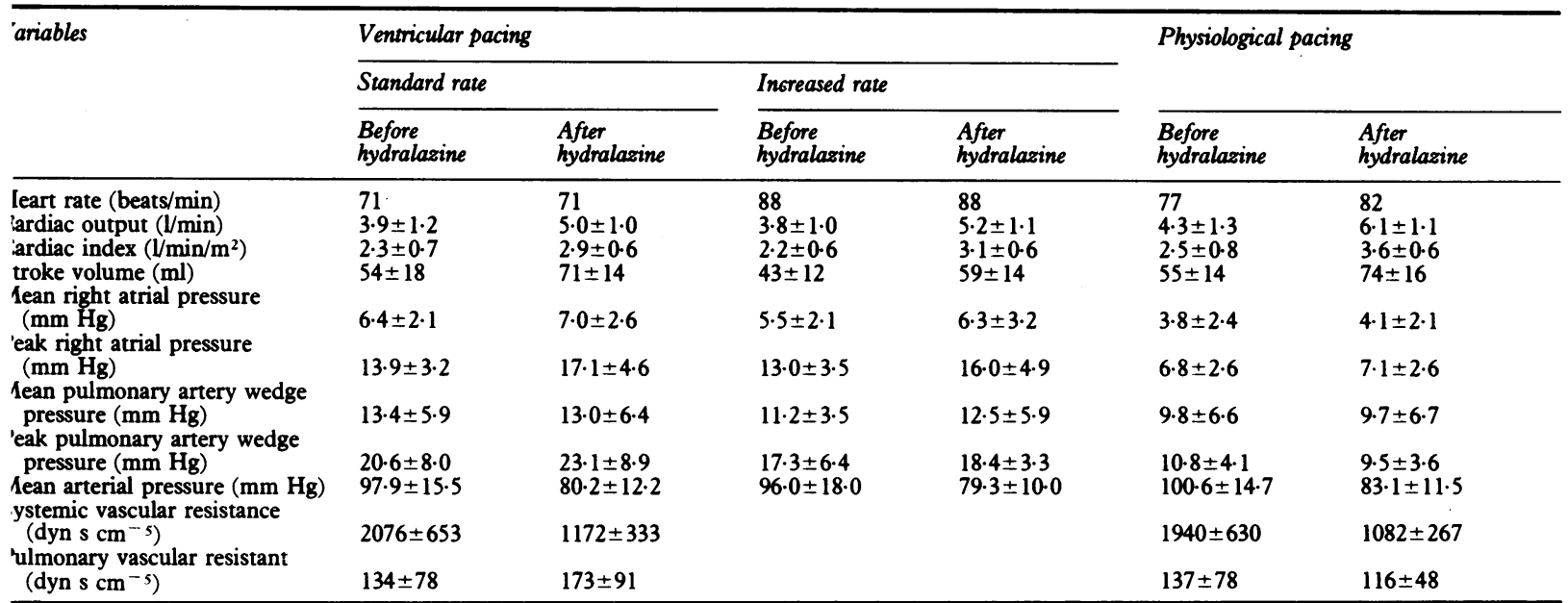

were then repeated after giving the arteriolar dilating drug hydralazine.

\section{Patients and methods}

Ten patients (six men and four women) were studied. Their ages ranged from 28 to 78 (mean 62) years. All had symptoms of dyspnoea or fatigue on moderate (seven) or mild (three) exertion (NYHA classes II and III) despite ventricular pacing. The indication for pacing was complete heart block in five patients, persistent 2:1 atrioventricular block in three, and intermittent bradycardia in two. All the patients had impaired left ventricular function as assessed by gated blood pool radionuclide ventriculography, with resting ejection fractions ranging from $12 \%$ to $43 \%$ (mean $30 \%$ ). All patients were receiving diuretics, but only one had clinical evidence of pulmonary congestion at the time of the study.

The study was approved by the local ethical committee, and all patients gave their informed consent. Six patients were studied at the time of elective pacing system revision, and the remaining four within three weeks of implantation of a multiprogrammable atrioventricular pacing system. In the first group a Cordis atrial $J$ shaped lead was inserted via the subclavian vein and positioned for atrial sensing or pacing or both. The existing ventricular lead was used for ventricular stimulation. In all patients a triple lumen thermodilution Swan-Ganz catheter was inserted percutaneously and passed to the pulmonary artery with the proximal lumen opening into the right atrium. Right atrial pressure, pulmonary artery pressure, and pulmonary artery wedge pressure were measured. Cardiac output measurements were made in triplicate. Systemic arterial pressure was measured using a sphygmomanometer cuff on the left or right arm. All patients were studied after an overnight fast and in the recumbent position.

Three different pacing patterns were used, and their order for individual patients randomised: (a) standard rate ventricular pacing (mean $71 / \mathrm{min}$ ); (b) increased rate ventricular pacing (mean rate $88 / \mathrm{min}$ ); and (c) atrial triggered pacing in nine patients or atrial pacing in one patient. Each pacing pattern was instituted for 10 minutes. Measurements were made when a steady state had been achieved. When measurements had been completed for each of the three patterns of pacing, hydralazine $20 \mathrm{mg}$ was infused intravenously over 15 minutes, and a further 20 minutes allowed to elapse before the different pacing patterns were repeated, again in random order.

\section{Results}

The results are shown in Tables 1 and 2 and Figs. 1-5. Statistical analysis was by the paired $t$ test. Results are expressed as mean \pm 1 standard deviation.

\section{BEFORE HYDRALAZINE}

There was no significant change in cardiac output when the ventricular pacing rate was increased from $71 / \mathrm{min}$ to $88 / \mathrm{min}$ : a decrease in stroke volume from $54 \pm 18 \mathrm{ml}$ to $43 \pm 12 \mathrm{ml}$ exactly compensated for the increase in rate. The mean ventricular rate during atrial triggered pacing was $77 / \mathrm{min}$, and there was a small but significant increase in cardiac output from $3.9 \pm 1.2 \mathrm{l} / \mathrm{min}$ to $4.3 \pm 1.3 \mathrm{l} / \mathrm{min}$, which was due to an increase in rate without change in stroke volume (Tables 1 and 2, Fig. 1).

There was no significant difference between the standard rate and increased rate of ventricular pacing 
Table 2 Individual results for cardiac output ( $/$ min) in each pacing mode. Unpaired results were excluded from comparative statistical analysis

\begin{tabular}{|c|c|c|c|c|c|c|}
\hline \multirow[t]{3}{*}{ Case No } & \multicolumn{3}{|c|}{ Before hydralasine } & \multicolumn{3}{|c|}{ After hydralasine } \\
\hline & \multicolumn{2}{|c|}{ Ventricular pacing } & \multirow{2}{*}{$\begin{array}{l}\text { Physiological } \\
\text { pacing }\end{array}$} & \multicolumn{2}{|c|}{ Ventricular pacing } & \multirow{2}{*}{$\begin{array}{l}\text { Physiological } \\
\text { pacing }\end{array}$} \\
\hline & Standard rate & Increased rate & & Standard rate & Increased rate & \\
\hline $\begin{array}{r}1 \\
2 \\
3 \\
4 \\
5 \\
6 \\
7 \\
8 \\
9 \\
10\end{array}$ & $\begin{array}{l}2.8 \\
6.6 \\
2.8 \\
4.9 \\
3.8 \\
3.5 \\
4.1 \\
2.5 \\
4.0 \\
3.5\end{array}$ & $\begin{array}{l}2.9 \\
5.5 \\
\\
3.2 \\
3.5 \\
4.1 \\
2.3 \\
4.7 \\
4.0\end{array}$ & $\begin{array}{l}4.3 \\
6.9 \\
3.3 \\
5.8 \\
3.2 \\
3.7 \\
3.8 \\
2.6 \\
5.0 \\
4.1\end{array}$ & $\begin{array}{l}4.8 \\
6.0 \\
3.7 \\
5.7 \\
4.8 \\
4.7 \\
6.3 \\
3.2 \\
5.9 \\
4.8\end{array}$ & $\begin{array}{l}3.2 \\
6.7 \\
4.3 \\
\\
5.1 \\
5.0 \\
5.2 \\
4.3 \\
6.1 \\
5.6\end{array}$ & $\begin{array}{l}5.1 \\
7.3 \\
6.4 \\
7.3 \\
5.1 \\
5.7 \\
6.6 \\
4.2 \\
7.7 \\
5.6\end{array}$ \\
\hline
\end{tabular}
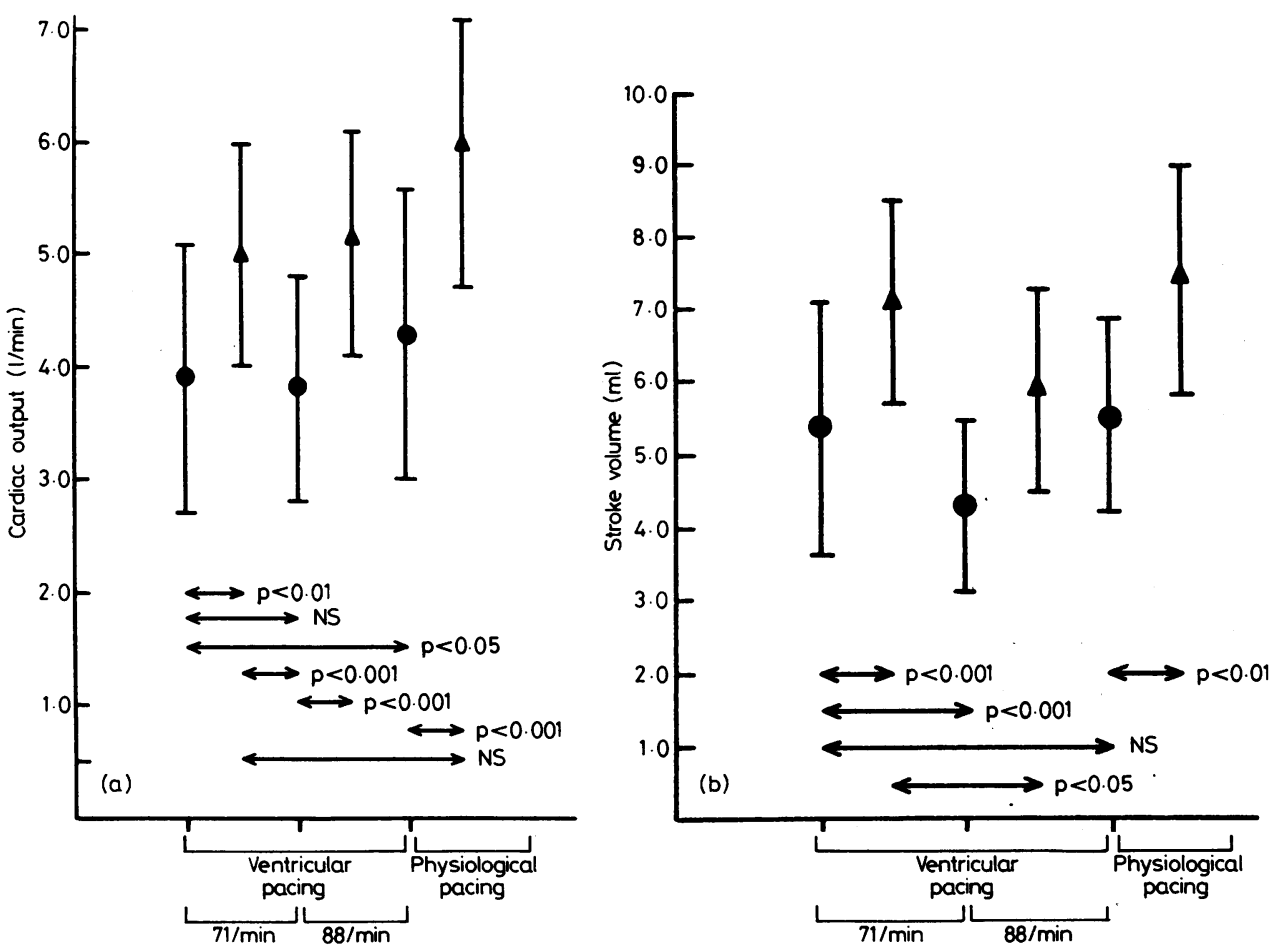

Fig. 1 Mean ( $\pm S E M)$ values for (a) cardiac output and (b) stroke volume before $(\bullet)$ and after $(\Delta)$ hydralazine in each pacing mode. Significance values are given for variables between each arrow.

with regard to mean or peak right atrial pressure or mean or peak pulmonary arterial wedge pressure, but atrial triggered pacing was associated with a $40 \%$ reduction in mean right atrial pressure $(p<0.01)$ and a $50 \%$ reduction in peak right atrial pressure $(p<0.001)$. There were similar reductions in pulmonary artery wedge pressure $(p<0.01, p<0.01)$ (Tables 1 and 3, Figs. 2 and 3).

No significant change was recorded in systemic arterial pressure, systemic vascular resistance, or pulmonary vascular resistance (Table 1, Fig. 4).
AFTER HYDRALAZINE

Cardiac output increased by approximately $30 \%$ from $3.9 \pm 1.2$ to $5.0 \pm 1.0(p<0.01)$ at the standard ventricular pacing rate as a result of a similar increase in stroke volume (Tables 1 and 2, Fig. 1). Mean systemic arterial pressure fell from $97 \cdot 9 \pm 15.5 \mathrm{~mm} \mathrm{Hg}$ to $80 \cdot 2 \pm 12 \cdot 2$ $\mathrm{mmHg}(\mathrm{p}<0.01)$ (Fig. 4). Systemic vascular resistance decreased by $41 \%(p<0.001)$, but there was no significant change in pulmonary vascular resistance. Mean right atrial pressure was not significantly altered, but there was an increase in peak right atrial 


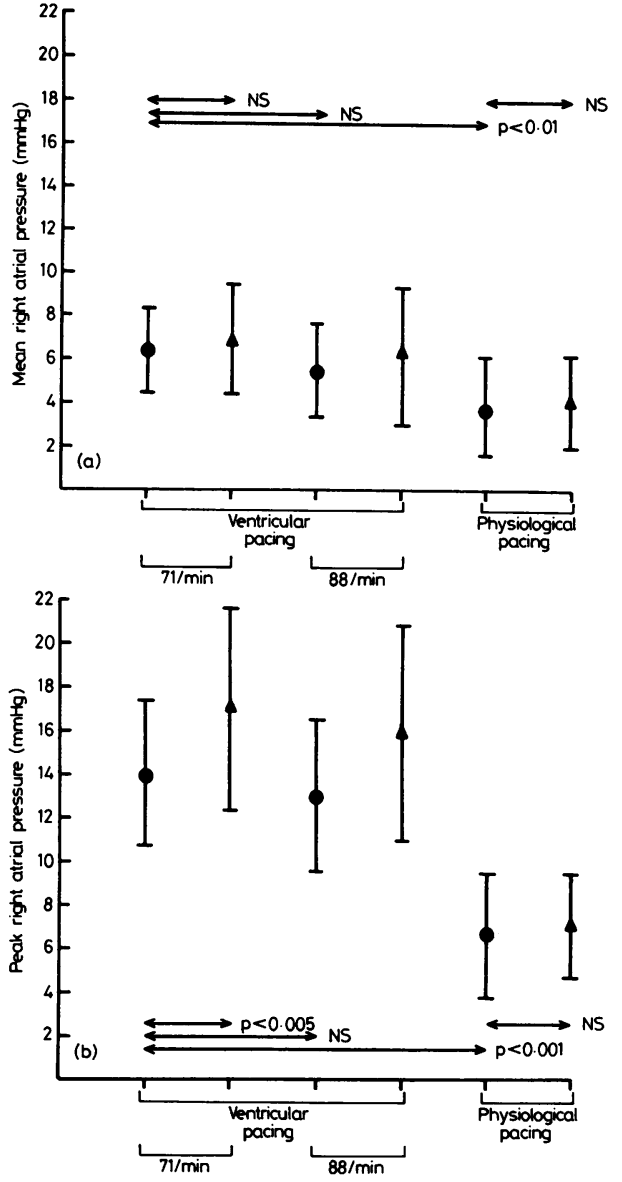

Fig. 2 Mean ( $\pm S E M)$ values of $(a)$ mean and $(b)$ peak right atrial pressure before $(\bullet)$ and after $(\Delta)$ hydralazine in each pacing mode. Significance values are given for variables between each arrow.

pressure from $13 \cdot 9 \pm 3 \cdot 2$ to $17 \cdot 1 \pm 4 \cdot 6$ (Fig. 2). There were no significant changes in mean or peak pulmonary artery wedge pressures, although peak wedge pressures tended to rise (Fig. 3).

There was no significant change in cardiac output or in atrial pressures when the ventricular pacing rate was increased to $88 / \mathrm{min}$; as before, the increase in rate was compensated for by a fall in stroke volume.

With atrial triggered pacing mean heart rate after hydralazine treatment was $82 / \mathrm{min}$ compared with $77 /$ min before hydralazine treatment; cardiac output was $42 \%$ greater than before hydralazine and $56 \%$ greater than with ventricular pacing before hydralazine, although this further increase was not statistically significant (Fig. 1). Mean right atrial pressure $(\mathrm{p}<0.01)$, peak right atrial pressure $(\mathrm{p}<0.001)$, mean pulmonary wedge pressure $(p<0.02)$, and peak wedge pressure $(p<0.01)$ were all lower with atrial triggered
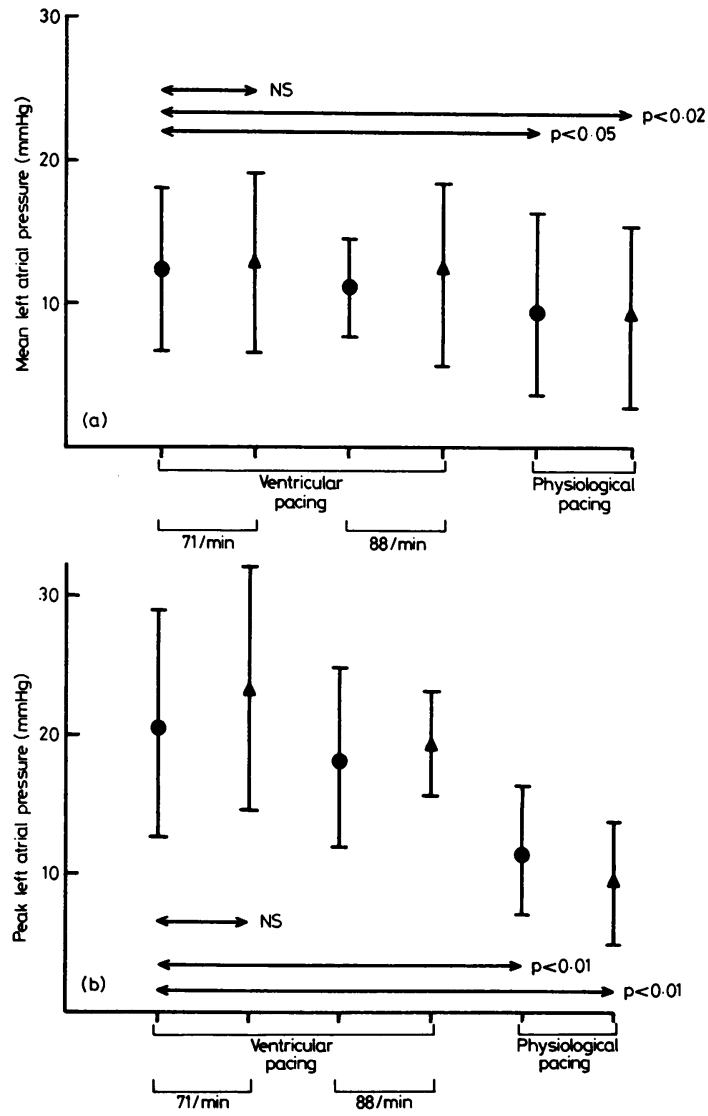

Fig. 3 Mean ( $\pm S E M)$ values of $(a)$ mean and (b) peak left atrial pressure before $(\bullet)$ and after $(\Delta)$ hydralazine in each pacing mode. Significance values are given for variables between each arrow.

pacing than with the standard or increased rate of ventricular pacing. The atrial pressures recorded with atrial triggered pacing after hydralazine were similar to those obtained with atrial triggered pacing before hydralazine (Tables 1 and 3, Figs. $2 \mathrm{~b}$ and $3 \mathrm{~b}$ ).

\section{Discussion}

In this group of patients studied at rest a change from fixed rate ventricular to atrial triggered ventricular pacing produced a small increase in cardiac output and a fall in right and left atrial pressure. Afterload reduction using hydralazine produced a larger increase in cardiac output but a tendency towards increased atrial pressures. A combination of afterload reduction with atrial triggered pacing preserved the increase in cardiac output but reduced left and right atrial pressures.

Although afterload reduction compared favourably 


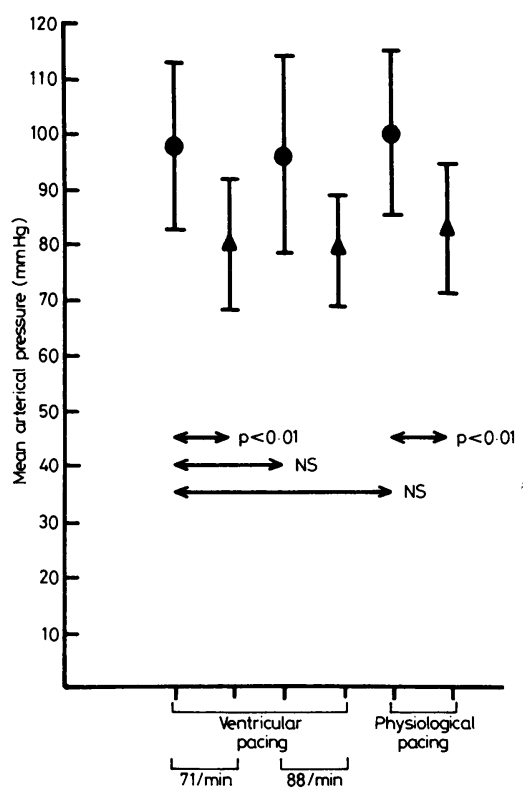

Fig. 4 Mean ( $\pm S E M)$ values of the mean arterial pressure, before $(\bullet)$ and after $(\Delta)$ hydralazine in each pacing mode. Significance values are given for variables between each arrow.

with physiological pacing in its effects on cardiac output and stroke volume, care should be taken in extrapolating these results to other patient groups. The mean resting cardiac index was low in our patients $\left(2.3 \pm 0.7 \mathrm{l} / \mathrm{min} / \mathrm{m}^{2}\right)$ and the mean systemic vascular resistance correspondingly high, which may account for the favourable response to vasodilatation. Other studies have shown that where left ventricular wall stress is not high afterload reduction can have a notably adverse haemodynamic and clinical effect. ${ }^{12}$ It is also not clear whether these results in recumbent patients at rest can be extrapolated to the ambulant patient. Systemic vascular resistance tends to fall with exercise anyway, and whether pharmacological afterload reduction is effective in these patients during exercise is at present conjectural. The relevance of cardiac output vis à vis atrial pressures in terms of subjective wellbeing and effort tolerance also remains to be explored.

The adverse haemodynamic effects of retrograde atrioventricular conduction, whereby delayed atrial activation causes regular contraction against closed atrioventricular valves, have been extensively studied, particular in animal models. ${ }^{13} 14$ Intermittent retrograde conduction occurred during ventricular pacing in three patients in the present study, but we were also impressed with the pronounced increased in peak right and left atrial pressures which could occur intermittently in patients with atrioventricular dissociation (Fig. 5). Increases of about $100 \%$ in peak right and left atrial pressure occurred when atrial and ventricular systole coincided (Figs. 3 and 5), and atrial pressure was inappropriately raised for up to $40 \%$ of the time during ventricular pacing at $71 / \mathrm{min}$.

Planning the best treatment for patients with heart failure and conduction disturbances is a complex problem. In some patients, an increase in resting cardiac output is the major priority, and this may be most effectively achieved using afterload reduction. A combination of this with physiological pacing in suitable patients will enhance the cardiac output and reduce the tendency of afterload reduction to increase atrial pressure. The possibility that pharmacological intervention might be an alternative to more expensive physiological pacemakers is attractive but requires evaluation in ambulatory as well as in resting patients. Conversely, other patients with an adequate cardiac output may be symptomatic because of transient inappropriate increases in atrial pressure and are much more likely to benefit from physiological pacing

Table 3 Individual results for mean and peak left atrial pressures ( $\mathrm{mm} \mathrm{Hg}$ ) in each pacing mode. Unpaired results were excluded from comparative statistical analysis

\begin{tabular}{|c|c|c|c|c|c|c|c|c|c|c|c|c|}
\hline \multirow[t]{4}{*}{ Case No } & \multicolumn{6}{|c|}{ Before hydralazine } & \multicolumn{6}{|c|}{ After hydralazine } \\
\hline & \multicolumn{4}{|c|}{ Ventricular pacing } & \multirow{2}{*}{\multicolumn{2}{|c|}{$\begin{array}{l}\text { Physiological } \\
\text { pacing }\end{array}$}} & \multicolumn{4}{|c|}{ Ventricular pacing } & \multirow{2}{*}{\multicolumn{2}{|c|}{$\begin{array}{l}\text { Physiological } \\
\text { pacing }\end{array}$}} \\
\hline & \multicolumn{2}{|c|}{ Standard rate } & \multicolumn{2}{|c|}{ Increased rate } & & & \multicolumn{2}{|c|}{ Standard rate } & \multicolumn{2}{|c|}{ Increased rate } & & \\
\hline & Mean & Peak & Mean & Peak & Mean & Peak & Mean & Peak & Mean & Peak & Mean & Peak \\
\hline $\begin{array}{r}1 \\
2 \\
3 \\
4 \\
5 \\
6 \\
7 \\
8 \\
9 \\
10\end{array}$ & $\begin{array}{r}-14 \\
16 \\
10 \\
14 \\
6 \\
10 \\
27 \\
10 \\
14\end{array}$ & $\begin{array}{l}-22 \\
20 \\
12 \\
20 \\
10 \\
12 \\
34 \\
22 \\
24\end{array}$ & $\begin{array}{r}\overline{12} \\
15 \\
\frac{14}{5} \\
- \\
\overline{10} \\
11\end{array}$ & $\begin{array}{l}\overline{16} \\
17 \\
20 \\
10 \\
14 \\
30 \\
14 \\
20\end{array}$ & $\begin{array}{r}-9 \\
8 \\
6 \\
14 \\
4 \\
3 \\
25 \\
8 \\
11\end{array}$ & $\begin{array}{l}\overline{11} \\
14 \\
- \\
6 \\
6 \\
\frac{12}{16}\end{array}$ & $\begin{array}{r}17 \\
10 \\
7 \\
14 \\
6 \\
10 \\
27 \\
16 \\
10\end{array}$ & $\begin{array}{l}\overline{30} \\
20 \\
- \\
\overline{14} \\
12 \\
32 \\
34 \\
20\end{array}$ & $\begin{array}{r}\overline{16} \\
16 \\
\overline{18} \\
\frac{2}{22} \\
10 \\
13\end{array}$ & $\begin{array}{l}\overline{22} \\
20 \\
- \\
- \\
14 \\
14 \\
24 \\
16 \\
20\end{array}$ & $\begin{array}{r}-12 \\
7 \\
6 \\
14 \\
7 \\
3 \\
25 \\
8 \\
5\end{array}$ & $\begin{array}{r}-14 \\
13 \\
8 \\
-7 \\
6 \\
30 \\
11 \\
6\end{array}$ \\
\hline
\end{tabular}




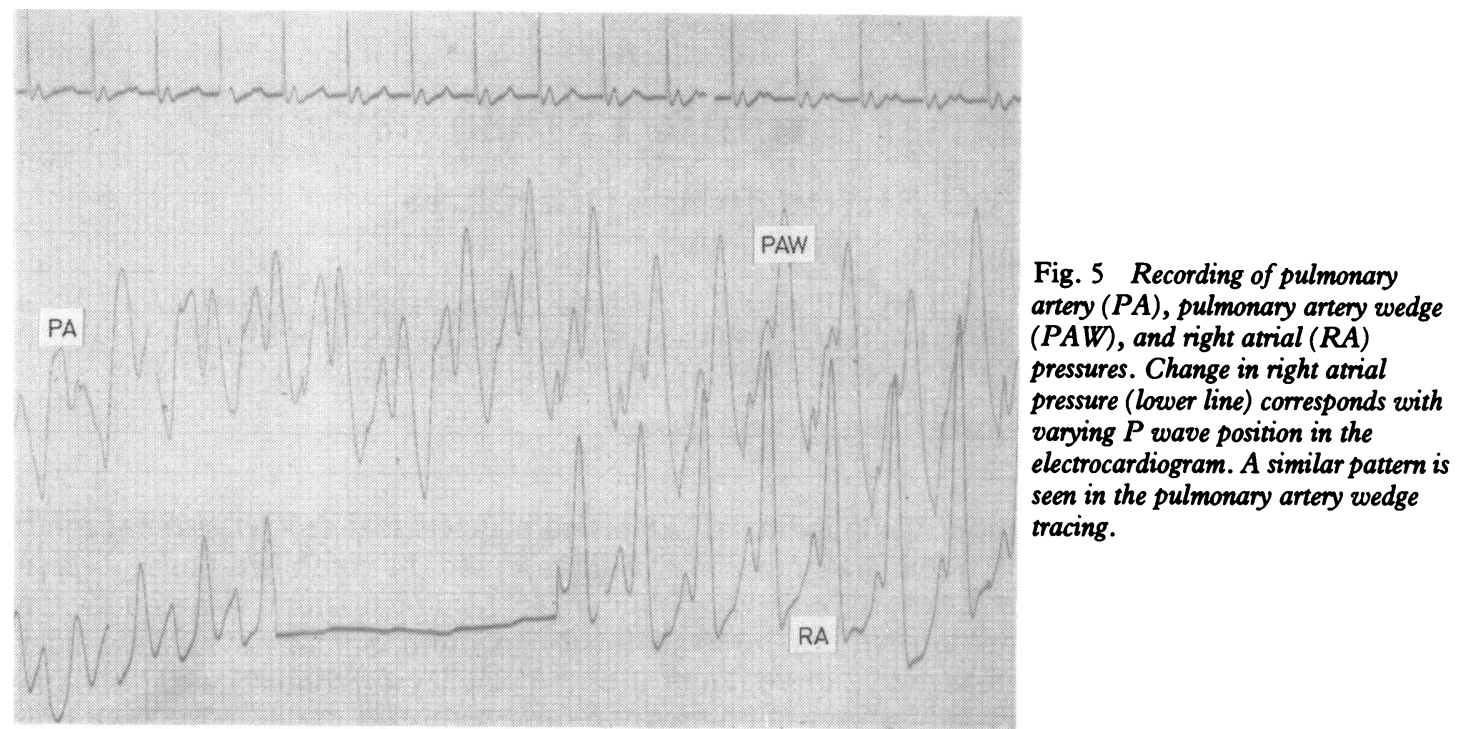

than from drug treatment. Measurements of resting cardiac output alone may not be helpful in selecting and evaluating the latter group.

\section{References}

1 Samet P, Castillo C, Bernstein WH. Hemodynamic sequelae of atrial, ventricular and sequential atrioventricular pacing in cardiac patients. Am Heart f 1966; 72: 725-9.

2 Geddes JS. Editorial: "Physiological" pacing. Br Heart $\mathcal{f}$ 1983; 50: 109-11.

3 Hartzler GO, Maloney JD, Curtis JJ, Barnhorst DA. Hemodynamic benefits of atrioventricular sequential pacing after cardiac surgery. Am $\mathcal{F}$ Cardiol 1977; 40: 232-6.

4 Chamberlain DA, Leinbach RC, Vassaux CE, Kastor JA, De Sanctis RW, Sanders CA. Sequential atrioventricular pacing in heart block complicating acute myocardial infarction. $N$ Engl f Med 1970; 282: 577-82.

5 Greenberg B, Chatterjee K, Parmley WW, Werner JA, Holly AN. The influence of left ventricular filling pressure on atrial contribution to cardiac output. Am Heart $\mathcal{f}$ 1979; 98: 742-51.

6 Karlöf I. Haemodynamic effect of atrial-triggered versus fixed rate pacing at rest and during exercise in complete heart block. Acta Med Scand 1975; 197: 195-206.

7 Donaldson RM, Fox K, Rickards AF. Initial experience with a physiological, rate responsive pacemaker. $\mathrm{Br} \mathrm{Med}$ f 1983; 286: 667-71.

8 Hayes DL, Vliestra RE, McGoon MD, Brown ML, Holmes DR, Gersh BJ. Comparison of exercise responses during ventricular and physiological pacing [Abstract]. PACE 1983; 6: 299.

9 Hand R, Boucher CA, Kanarek DJ, Okada R, Pohost GM, Harthorne JW. Exercise cardiopulmonary assessment with dual chamber versus ventricular pacing [Abstract]. PACE 1983; 6: 300.

10 Perrins EJ, Morley CA, Chan SL, Sutton R. Randomised controlled trial of physiological and ventricular pacing. $\mathrm{Br}$ Heart $\mathcal{f}$ 1983; 50: 112-7.

11 Mason DT. Symposium perspective. Am $\mathcal{F}$ Med 1978; 65: 101-5.

12 Packer M, Meller J, Medina N, Gorlin R, Herman MV. Importance of left ventricular chamber size in determining the response to hydralazine in severe chronic heart failure. $N$ Engl f Med 1980; 303: 250-5.

13 Ogawa S, Dreifus LS, Shenoy PN, Brockman SK, Berkovitz BV. Hemodynamic consequences of atrioventricular and ventriculoatrial pacing. PACE 1978; 1: 8-15.

14 Brockman SK. Cardiodynamics of complete heart block. Am $\mathcal{F}$ Cardiol 1965; 16: 72-83. 